УДК 665.642.5-404:665.64.097.3:543.544.3:543.51

МНОГОКРАТНОЕ ИСПОЛЬЗОВАНИЕ НАНОРАЗМЕРНОГО

МЕТАЛЛСОДЕРЖАЩЕГО КАТАЛИЗАТОРА ЦИНКА ПРИ КРЕКИНГЕ ПРЯМОГОННОГО МАЗУТА

\title{
MULTIPLE USE OF NANOSIZED METAL-CONTAINING ZINC CATALYST IN CRACKING OF STRAIGHT-RUN FUEL OIL
}

И.А. Мустафин, О.М. Судакова, К.Е. Станкевич, Р.Н. Галиахметов, Э.Р. Валинурова, А.Р. Ханов

Уфимский государственный нефтяной технический университет,

Башкирский государственный университет, г. Уфа, Российская Федерация

Ildar A. Mustafin, Oksana M. Sudakova, Clara E. Stankevich, Rail N. Galiakhmetov, Elvira R. Valinurova, Aidar R. Khanov

Ufa State Petroleum Technological University, Bashkir State University,Ufa, Russian Federation e-mail: iamustafin@gmail.com

Аннотация. В работе представлены результаты многократного использования цинксодержащего нанокатализатора при крекинге прямогонного мазута (ПМ). Прямогонный мазут из западносибирской нефти подвергали каталитическому крекингу на аппарате АPH-2 по ГОСТ 11011-64. Катализатор получен из 2-этилгксаноата цинка (2ЭГЦ) в среде прямогонного мазута при температуре его кипения, представляет собой наночастицы оксида, сульфида цинка и металла размером до 80-90 нм. Для исследования возможности многократного применения нанокатализатора была проведена серия опытов. После каждого процесса каталитической разгонки пробы нефтяного сырья в оставшийся кубовый 
остаток вводили свежую порцию исходного сырья в таком количестве, чтобы общая масса образца не превышала массу первоначально взятой

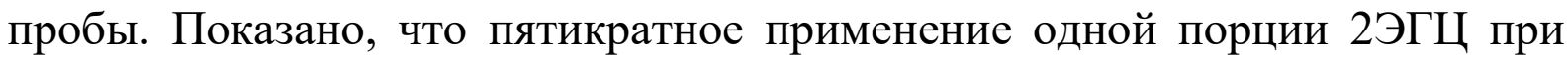
каталитическом крекинге ПМ незначительно снижает выход дистиллята. Выход жидкого дистиллята практически не меняется при пятикратно введённой свежей порции мазута в кубы предшествующих проб. Наблюдается незначительный спад выхода дистиллята с $38 \%$ до $30 \%$ только после первого опыта. Массовая доля кубовых остатков постепенно снижается, а выход газовой части (потери) повышается с 5 \% до 20 \%.

Методом SARA-анализа установлен групповой состав прямогонного мазута до и после каталитической разгонки Показано, что введение 2ЭГЦ существенно меняет групповой состав кубовых остатков в процессе каталитического крекинга. Постепенно снижается выход фракции мальтенов и наблюдается резкий рост фракции карбенов. Показано, что в реакционной среде смеси прямогонного мазута и 0,02 \% масс. 2ЭГЦ происходят реакции каталитического крекинга, сопровождающиеся уменьшением массовой доли насыщенных углеводородов, повышением концентрации ароматических соединений, что отражается на групповом составе полученных кубов.

Abstract. The paper presents the results of multiple use of a zinc-containing nanocatalyst in the cracking of straight-run fuel oil. Straight-run fuel oil from West Siberian oil was subjected to catalytic cracking on an ARN-2 apparatus according to GOST 11011-64. The catalyst is obtained from zinc 2-ethylxanoate in a medium of straight-run fuel oil at its boiling point; it is nanoparticles of oxide, zinc sulfide and metal up to 80-90 nm. A series of experiments was carried out to investigate the possibility of multiple use of the nanocatalyst. After each process of catalytic distillation of a sample of petroleum feedstock, a fresh portion of the feedstock was introduced into the bottom residue in such an amount that the total mass of the sample did not exceed the mass of the initially taken sample. It has been shown that the fivefold application of one portion of zinc 2-ethylxanoate in 
the catalytic cracking of straight-run fuel oil insignificantly reduces the distillate yield. The yield of liquid distillate practically does not change with a fivefold fresh portion of fuel oil introduced into the stills of the previous samples. There is a slight decline in the distillate yield from $38 \%$ to $30 \%$ only after the first experiment. The mass fraction of the bottoms is gradually decreasing, and the yield of the gas portion (losses) increases from $5 \%$ to $20 \%$.

The group composition of straight-run fuel oil before and after catalytic distillation was established using SARA analysis. It is shown that the introduction of zinc 2-ethylxanoate significantly changes the group composition of bottoms in the process of catalytic cracking. The yield of the maltenes fraction gradually decreases and a sharp increase in the carbenes fraction is observed. It is shown that in the reaction medium a mixture of straight-run fuel oil and $0.02 \%$ of the mass. zinc 2-ethylxanoate, catalytic cracking reactions occur, accompanied by a decrease in the mass fraction of saturated hydrocarbons, an increase in the concentration of aromatic compounds, which is reflected in the group composition of the obtained cubes.

Ключевые слова: мазут; крекинг; катализатор; групповой состав; мальтены; асфальтены; карбены; 2-этилгексаноат цинка

Key words: fuel oil; cracking; catalyst; group composition; maltenes; asphaltenes; carbenes; zinc 2-ethylhexanoate

В процессах каталитического крекинга, гидрокрекинга и висбрекинга широкое применение находят гетерогенные катализаторы, содержащие молибден, никель, кобальт, вольфрам и другие металлы $[1,2]$. Высокое содержание различных гетероатомных металлорганических соединений и асфальтенов в сырье затрудняет использование существующих технологий при переработке тяжелых углеводородов из-за быстрого отравления классических катализаторов [3]. Поэтому получение каталитических систем непосредственно в ходе процесса крекинга тяжелого углеводородного 
сырья представляется актуальным. Ранее нами было обнаружено, что термическое воздействие на тяжелые нефтяные остатки и тяжелые нефти, содержащие нефтерастворимые органические соли металлов, приводит к образованию наноразмерных суспензий металлов [4-10]. Так, при термическом воздействии до $300{ }^{\circ} \mathrm{C}$ на мазут западносибирской нефти, содержащий 2-этилгексаноат никеля, установлено образование наночастиц с размером порядка $80 \mathrm{Hм}$.

В продолжение этих работ нами проводится поиск других, более доступных металлсодержащих катализаторов для крекинга тяжелых компонентов нефти. Целью настоящей работы является получение в прямогонном мазуте наноразмерных суспензий соединений цинка и изучение их каталитического действия при многократном повторении циклов крекинга.

В качестве объекта исследований был использован прямогонный мазут, полученный из западносибирской нефти, некоторые характеристики которого приведены в таблице 1.

Таблица 1. Групповой состав прямогонного мазута

\begin{tabular}{|c|c|}
\hline \multicolumn{1}{|c|}{ Фракция } & Содержание, \% масс. \\
\hline Мальтены: & 91,10 \\
насыщенные углеводороды & 25,10 \\
ароматические ув углеводороды & 40,10 \\
смолы & 31,80 \\
\hline Асфальтены & 6,70 \\
\hline Карбены & 0,03 \\
\hline
\end{tabular}

В качестве прекурсора катализатора была использована металлсодержащая 0,1 \% масс. добавка 2-этилгексаноата цинка. 
Термографические исследования проводили на термоанализаторе TGA/DSCI фирмы «MettlerToledo» (Швейцария). Фазовый состав образцов исследовали с помощью дифрактометра ДРОН-3М.

\section{Результаты и их обсуждение}

Для установления процесса образования и термической устойчивости наночастиц в среде углеводородов были проведены анализы проб прямогонного мазута (ПМ), содержащего 2-ЭГЦ. Для этого пробы отбирали во время постепенного нагревания смеси до $365^{\circ} \mathrm{C}$ со скоростью $10^{\circ} \mathrm{C} / \mathrm{Mин,}$ а также после кипячения при температуре $355-365^{\circ} \mathrm{C}$ через 15,30 и 60 мин. В разбавленных толуолом 1 : 10 пробах ПМ определяли далее размеры частиц. Установлено, что размер частиц меняются от 20 до 120 нм, причем средний размер наночастиц достигал 50 нм. Кипячение смеси в течение первых 15 мин способствовало росту размера частиц до $130 \mathrm{Hм.}$ Последующее более длительное кипячение в течение 30 и 60 мин привело к стабилизации размера частиц. Средний размер наночастиц соответствовал 90 нм. Устойчивость образовавшихся цинксодержащих наночастиц позволяет использовать 2ЭГЦ в качестве прекурсора катализатора при каталитическом крекинге тяжелых нефтяных остатках.

Для исследования возможности многократного применения нанокатализатора была проведена серия опытов. После каждого процесса каталитической разгонки пробы нефтяного сырья в оставшийся кубовый остаток вводили свежую порцию исходного сырья в таком количестве, чтобы общая масса образца не превышала массу первоначально взятой

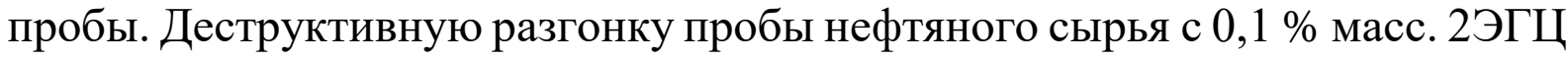
проводили в аппарате Энглера согласно ГОСТ 11011-64. Результаты отгонки приведены в таблицах 2 и 3. 
Таблица 2. Температура паров при многократном использовании 2ЭГЦ в процессе каталитического крекинга прямогонного мазута

\begin{tabular}{|c|c|c|c|c|c|}
\hline \multirow[b]{2}{*}{$\begin{array}{c}\text { Отгон, } \\
\text { мл }\end{array}$} & \multicolumn{5}{|c|}{ Температура паров } \\
\hline & $\begin{array}{l}\text { I. } \\
\Pi M+Z n\end{array}$ & $\begin{array}{c}\text { II. } \\
\text { Куб I + ПМ }\end{array}$ & $\begin{array}{c}\text { III. } \\
\text { Куб II + ПМ }\end{array}$ & $\begin{array}{c}\text { IV. } \\
\text { Куб III + ПМ }\end{array}$ & $\begin{array}{c}\text { V. } \\
\text { Куб IV + ПМ }\end{array}$ \\
\hline 5 & 112 & 130 & 125 & 130 & 182 \\
\hline 10 & 118 & 160 & 160 & 230 & 212 \\
\hline 15 & 120 & 182 & 188 & 230 & 212 \\
\hline 20 & 125 & 185 & 230 & 235 & 200 \\
\hline
\end{tabular}

Таблица 3. Температура кубов при многократном использовании 2ЭГЦ в процессе каталитического крекинга прямогонного мазута

\begin{tabular}{|c|c|c|c|c|c|}
\hline \multirow{2}{*}{$\begin{array}{c}\text { Отгон, } \\
\text { мл }\end{array}$} & \multicolumn{5}{|c|}{ Температура кубов } \\
\cline { 2 - 6 } & $\begin{array}{c}\text { I. } \\
\text { ПМ + Zn }\end{array}$ & $\begin{array}{c}\text { II. } \\
\text { Куб I + ПM }\end{array}$ & $\begin{array}{c}\text { III. } \\
\text { Куб II + ПM }\end{array}$ & $\begin{array}{c}\text { IV. } \\
\text { Куб III + ПM }\end{array}$ & $\begin{array}{c}\text { V. } \\
\text { Куб IV + ПM }\end{array}$ \\
\hline 5 & 410 & 410 & 415 & 419 & 417 \\
\hline 10 & 419 & 419 & 420 & 322 & 421 \\
\hline 15 & 425 & 422 & 424 & 432 & 430 \\
\hline 20 & 427 & 424 & 430 & 435 & 431 \\
\hline
\end{tabular}

Как видно из приведенных таблиц 2 и 3 , температура паров и кубовых остатков постепенно возрастает при проведении каталитической разгонки прямогонного мазута после добавления свежей его порции к кубовому остатку, содержащему нанокатализатор. Было установлено, что введение 2ЭГЦ в ПМ способствует повышению выхода жидкого дистиллята по сравнению с выходом дистиллята при термической разгонке с 39 \% до $55 \%$. Гистограмма, приведенная на рисунке 1, показывает эффективность многократного использования полученного в среде нефтепродукта цинксодержащего нанокатализатора. 


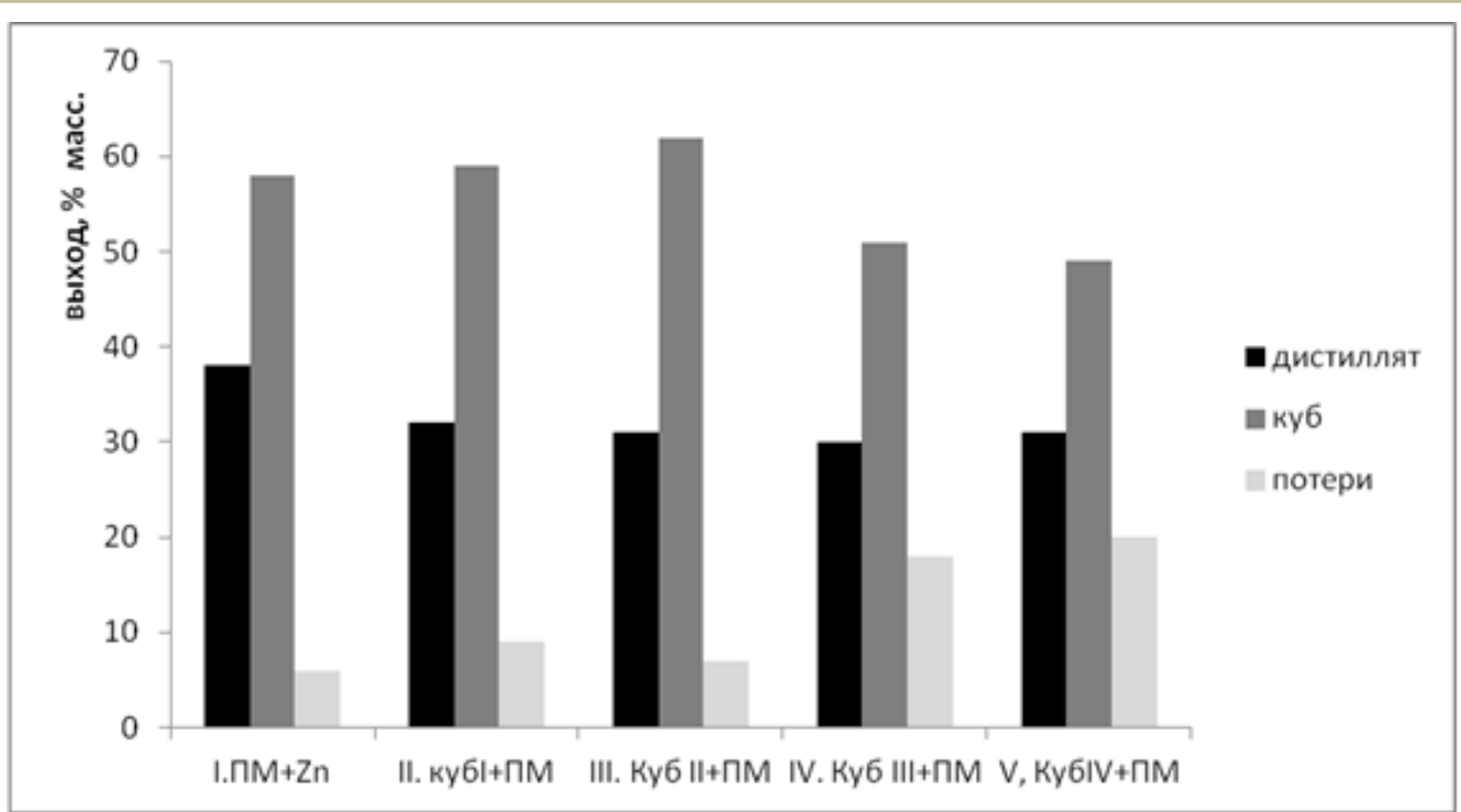

Рисунок 1. Материальный баланс многократного использования 2-этилгексаноата цинка при крекинге прямогонного мазута

Как видно из рисунка 1, выход жидкого дистиллята практически не меняется при пятикратно введённой свежей порции мазута в кубы предшествующих проб. Наблюдается незначительный спад выхода дистиллята с 38 \% до $30 \%$ только после первого опыта. Массовая доля кубовых остатков постепенно снижается, а выход газовой части (потери) повышается с 5 \% до $20 \%$.

Полученные экспериментальные данные хорошо согласуются с результатами исследования группового состава кубовых остатков прямогонного мазута. Групповой состав ПМ исследовали методом SARAанализа, основанного на селективном растворении фракций мальтенов ( $\gamma$-фракция), асфальтенов ( $\beta$-фракция) в н-гептане и толуоле соответственно по схеме (рисунок 2) [9]. Карбены ( $\alpha$-фракция) не растворяются в приведённых растворителях и представляют собой наиболее тяжелую фракцию [10]. 


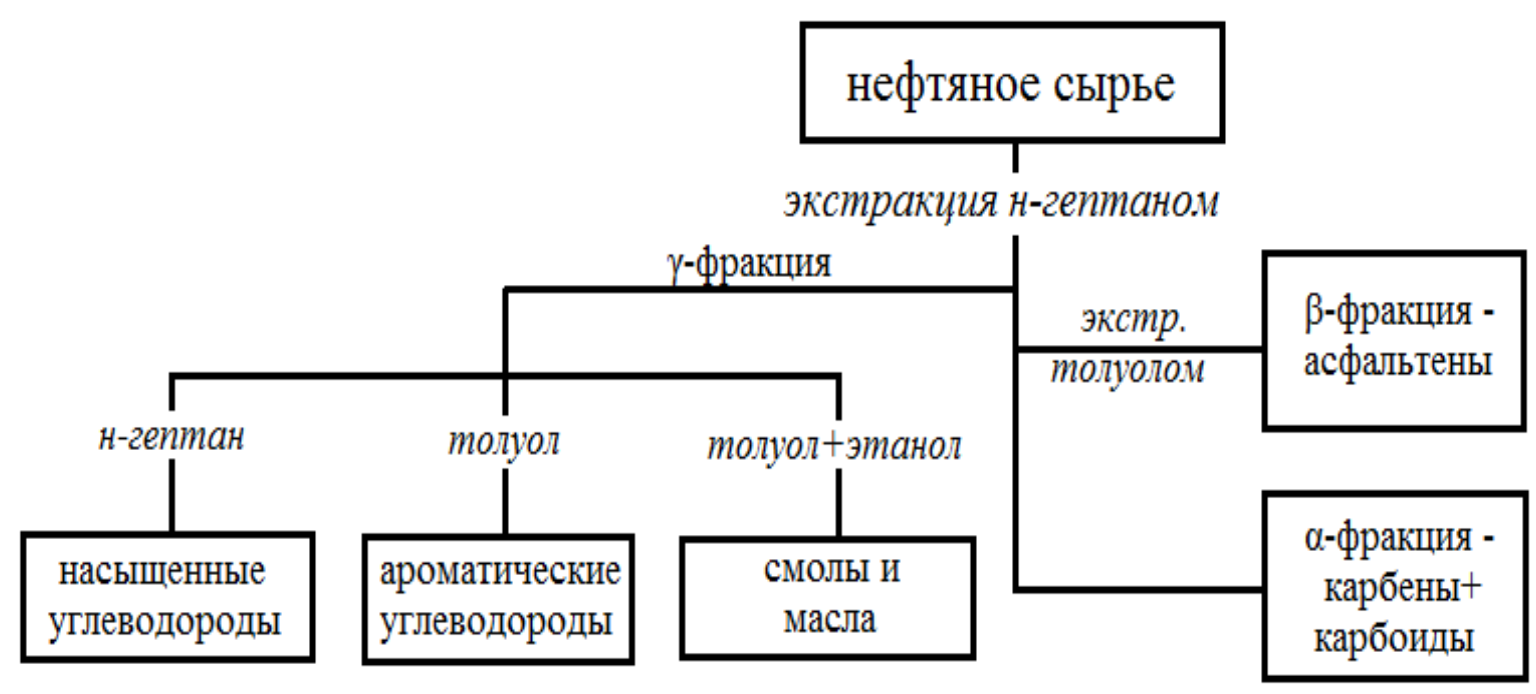

Рисунок 2. Схема разделения нефтяного остатка методом SARA

Результаты исследования группового состава кубовых остатков ПМ приведен в таблице 4.

Таблица 4. Групповой состав кубовых остатков термического и каталитического крекинга прямогонного мазута

\begin{tabular}{|l|c|c|c|}
\hline \multicolumn{1}{|c|}{ Образец } & $\begin{array}{c}\text { г-фракция, } \\
\text { \% масс. }\end{array}$ & $\begin{array}{c}\beta \text {-фракция, } \\
\text { \% масс. }\end{array}$ & $\begin{array}{c}\text { б-фракция, } \\
\text { \% масс. }\end{array}$ \\
\hline $\begin{array}{l}\text { Куб ПМ } \\
\text { (крекинг } \\
\text { без 2ЭГЦ) }\end{array}$ & 91,1 & 6,7 & 0,1 \\
\hline $\begin{array}{l}\text { Куб I } \\
\text { (ПМ + 2ЭГЦ) }\end{array}$ & 17,5 & 8,1 & 70,4 \\
\hline $\begin{array}{l}\text { Куб V } \\
\text { (куб IV + ПМ) }\end{array}$ & 11,3 & 7,6 & 80,7 \\
\hline
\end{tabular}

Изменения в качественном составе фракции мальтенов представлены в таблице 5. 
Таблица 5. Фракционный состав мальтенов кубовых остатков каталитического крекинга прямогонного мазута

\begin{tabular}{|l|c|c|c|}
\hline \multicolumn{1}{|c|}{ Образец } & $\begin{array}{c}\text { Насыщенные } \\
\text { углеводороды, } \\
\text { \% масс. }\end{array}$ & $\begin{array}{c}\text { Ароматические } \\
\text { углеводороды, } \\
\text { \% масс. }\end{array}$ & $\begin{array}{c}\text { Смолы, } \\
\text { \% масс. }\end{array}$ \\
\hline $\begin{array}{l}\text { Куб ПМ } \\
\text { (крекинг } \\
\text { без 2ЭГЦ) }\end{array}$ & 39,9 & 37,8 & 19,6 \\
\hline $\begin{array}{l}\text { Куб I } \\
\text { (ПМ + 2ЭГЦ) }\end{array}$ & 33,9 & 43,2 & 21,1 \\
\hline $\begin{array}{l}\text { Куб V } \\
\text { (куб IV + ПМ) }\end{array}$ & 31,9 & 54,7 & 11,1 \\
\hline
\end{tabular}

Из приведенных данных следует, что введение в прямогонный мазут

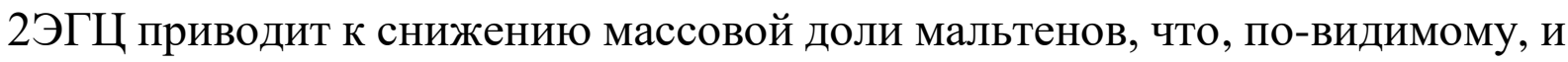
способствует повышению выхода жидкого дистиллята; приводит к резкому росту $\alpha$-фракции карбенов. Причем рост последних наблюдается при многократном использовании порции катализатора. В мальтенах снижается массовая доля насыщенных углеводородов, и растет содержание ароматических углеводородов. То есть многократное применение катализатора постепенно способствует образованию конденсированных ароматических систем.

\section{Выводы}

Таким образом, на основании полученных экспериментальных данных можно сделать вывод о возможности использования 2-этилгексаноата цинка в качестве прекурсора нанокатализатора для последующего его применения в каталитической разгонке прямогонного мазута. Возможно многократное использование небольшой добавки 2ЭГЦ для повышения выхода жидкого дистиллята без снижения каталитической активности образующихся наночастиц катализатора.

Работа выполнена при поддержке Гранта Республики Башкортостан молодым ученым. 


\section{Список используемых источников}

1. Хаджиев С.Н. Крекинг нефтяных фракций на цеолитсодержащих катализаторах. М.: Химия, 1982. 280 с.

2. Ахметов С.А., Ишмияров М.Х., Кауфман А.А. Технология переработки нефти, газа и твердых горючих ископаемых. СПб.: Недра, 2009. $827 \mathrm{c}$.

3. Ахметов С.А. Технология глубокой переработки нефти и газа. СПб.: Недра, 2013. 544 с.

4. Хаджиев С.Н. Наногетерогенный катализ - новый сектор нанотехнологий в химии и нефтехимии // Нефтехимия. 2011. Т. 51. № 1. C. 3- 16 .

5. Мустафин И.А., Судакова О.М., Галиахметов Р.Н., Ахметов А.Ф., Мустафин А.Г. Рентгенофазные исследования остатков термокаталитической деструкции нефтепродуктов в присутствии 2-этилгексаноатов цинка и никеля // Мир нефтепродуктов. Вестник нефтяных компаний. 2016. № 12. С. 18-23.

6. Пат. 2472842 РФ, МПК С 10 G 31/00. Применение органической соли для увеличения глубины переработки углеводородсодержащего сырья и способ увеличения глубины переработки углеводородсодержащего сырья / Р.Н. Галиахметов, А.Г. Мустафин. 2011151658/04, Заявлено 16.12.2011; Опубл. 20.01.2013. Бюл. 2.

7. Пат. 2485167 РФ, МПК С 10 G 9/00. Способ переработки углеводородсодержащего сырья (варианты) / Р.Н. Галиахметов, А.Г. Мустафин. 2012103649/04, Заявлено 02.02.2012; Опубл. 20.06.2013. Бюл. 17.

8. Пат. 2486130 РФ, МПК В 82 В 3/00. Способ получения наночастиц металлов / Р.Н. Галиахметов, А.Г. Мустафин. 2011151591/04, Заявлено 16.12.2011; Опубл. 27.06.2013. Бюл. 18. 
9. Мустафин И.А., Абдуллин М.Ф., Судакова О.М., Мустафин А.Г., Галиахметов Р.Н., Валинурова Э.Р. Деструктивное превращение газойля в присутствии наноразмерного катализатора на основе никеля // Нефтехимия. 2018. T. 58. № 3. C. 275-281. DOI: 10.7868/S0028242118030036.

10. Galiakhmetov R.N., Mustafin I., Sudakova O., Valinurova E. Thermographic Studies of Vacuum Gas Oil // International Journal of Applied Engineering Research. 2016. Vol. 11. No. 23. P. 11184-11188.

11. Carbognani L., Izquierdo A. Preparative and Automated Compound Class Separation of Venezuelan Vacuum Residua by High Performance Liquid Chromatography // Journal of Chromatography. 1989. Vol. 484. P. 399-408.

12. Беляева Л.С., Валинурова Э.Р. Влияние термообработки нефтяного сырья на групповой состав пека // Вестник Башкирского университета. 2017. T. 22. № 4. C. 1001-1005.

\section{References}

1. Khadzhiev S.N. Kreking neftyanykh fraktsii na tseolitsoderzhashchikh katalizatorakh [Cracking of Petroleum Fractions on Zeolite Catalysts]. Moscow, Khimiya Publ., 1982. 280 p. [in Russian].

2. Akhmetov S.A., Ishmiyarov M.Kh., Kaufman A.A. Tekhnologiya pererabotki nefti, gaza i tverdykh goryuchikh iskopaemykh [Oil, Gas and Solid Fossil Fuels Refining Technology]. Saint Petersburg, Nedra Publ., 2009. 827 p. [in Russian].

3. Akhmetov S.A. Tekhnologiya glubokoi pererabotki nefti $i$ gaza [Deep Processing Technology of Oil and Gas]. Saint Petersburg, Nedra Publ., 2013. 544 p. [in Russian].

4. Khadzhiev S.N. Nanogeterogennyi kataliz - novyi sektor nanotekhnologii $\mathrm{v}$ khimii i neftekhimii [Nanoheterogeneous Catalysis - a New Sector of Nanotechnology in Chemistry and Petrochemistry]. Neftekhimiya - Petroleum Chemistry, 2011, Vol. 51, No. 1, pp. 3-16. [in Russian]. 
5. Mustafin I.A., Sudakova O.M., Galiakhmetov R.N., Akhmetov A.F., Mustafin A.G. Rentgenofaznye issledovaniya ostatkov termokataliticheskoi destruktsii nefteproduktov v prisutstvii 2-etilgeksanoatov tsinka i nikelya [The XRay Phase Diffraction Studies of Petroleum Residues after Catalytic Thermal Destruction in the Presence of Zinc and Nickel 2-Ethylhexanoate]. Mir nefteproduktov. Vestnik neftyanykh kompanii - World of Oil Products. The Oil Companies' Bulletin, 2016, No. 12, pp. 18-23. [in Russian].

6. Galiakhmetov R.N., Mustafin A.G. Primenenie organicheskoi soli dlya uvelicheniya glubiny pererabotki uglevodorodsoderzhashchego syr'ya i sposob uvelicheniya glubiny pererabotki uglevodorodsoderzhashchego syr'ya [The use of Organic Salt to Increase the Depth of Processing of Hydrocarbon-Containing Raw Materials and a Method for Increasing the Depth of Processing of Hydrocarbon-Containing Raw Materials]. Patent RF, No. 2472842, 2013. [in Russian].

7. Galiakhmetov R.N., Mustafin A.G. Sposob pererabotki uglevodorodsoderzhashchego syr'ya (varianty) [Method for Processing Hydrocarbon-Containing Raw Materials (Options)]. Patent RF, No. 2485167, 2013. [in Russian].

8. Galiakhmetov R.N., Mustafin A.G. Sposob polucheniya nanochastits metallov [Method of Obtaining Metal Nanoparticles]. Patent RF, No. 2486130, 2013. [in Russian].

9. Mustafin I.A., Abdullin M.F., Sudakova O.M., Mustafin A.G., Galiakhmetov R.N., Valinurova E.R. Destruktivnoe prevrashchenie gazoilya v prisutstvii nanorazmernogo katalizatora na osnove nikelya [Destructive Transformation of Gas Oil in the Presence of a Nano-Sized Catalyst Based on Nickel]. Neftekhimiya - Petroleum Chemistry, 2018, Vol. 58, No. 3, pp. 275-281. DOI: 10.7868/S0028242118030036. [in Russian].

10. Galiakhmetov R.N., Mustafin I., Sudakova O., Valinurova E. Thermographic Studies of Vacuum Gas Oil. International Journal of Applied Engineering Research, 2016, Vol. 11, No. 23, pp. 11184-11188. 
11. Carbognani L., Izquierdo A. Preparative and Automated Compound Class Separation of Venezuelan Vacuum Residua by High Performance Liquid Chromatography. Journal of Chromatography, 1989, Vol. 484, pp. 399-408.

12. Belyaeva L.S., Valinurova E.R. Vliyanie termoobrabotki neftyanogo syr'ya na gruppovoi sostav peka [The Influence of Temperature of Heat Treatment of Oil on the Group Composition of Pitch]. Vestnik Bashkirskogo universiteta Bulletin of Bashkir University, 2017, Vol. 22, No. 4, pp. 1001-1005. [in Russian].

\section{Сведения об авторах}

\section{About the authors}

Мустафин Ильдар Ахатович, канд. техн. наук, доцент кафедры «Технология нефти и газа», УГНТУ, г. Уфа, Российская Федерация

Ildar A. Mustafin, Candidate of Engineering Sciences, Assistant Professor of Oil and Gas Processing Department, USPTU, Ufa, Russian Federation

e-mail: iamustafin@gmail.com

Судакова Оксана Минигуловна, аспирант кафедры «Управление качеством», Башкирский государственный университет, г. Уфа, Российская Федерация

Oksana M. Sudakova, Post-graduate Student of Quality Control Department, Bashkir State University, Ufa, Russian Federation

e-mail: gold-dragon@inbox.ru

Станкевич Клара Евгеньевна, канд. техн. наук, доцент кафедры «Технология нефти и газа», УГНТУ, г. Уфа, Российская Федерация

Clara E. Stankevich, Candidate of Engineering Sciences, Assistant Professor of Oil and Gas Processing Department, USPTU, Ufa, Russian Federation e-mail: clara.stankevich@gmail.com 
Галиахметов Раиль Нигматьянович, д-р техн. наук, профессор, заведующий кафедрой «Управление качеством», Башкирский государственный университет, г. Уфа, Российская Федерация

Rail N. Galiakhmetov, Doctor of Engineering Sciences, Professor, Head of Quality Control Department, Bashkir State University, Ufa, Russian Federation e-mail: rail007@mail.ru

Валинурова Эльвира Рафиковна, канд. техн. наук, доцент кафедры общей, аналитической и прикладной химии, УГНТУ, г. Уфа, Российская Федерация

Elvira R. Valinurova, Candidate of Engineering Sciences, Assistant Professor of General, Analytical and Applied Chemistry Department, USPTU, Ufa, Russian Federation

e-mail: valinurova_elvira@mail.ru

Ханов Айдар Рустамович, аспирант кафедры «Технология нефти и газа», УГНТУ, г. Уфа, Российская Федерация

Aidar R. Khanov, Post-graduate Student of Oil and Gas Processing Department, USPTU, Ufa, Russian Federation e-mail: aidar1994_10@mail.ru 